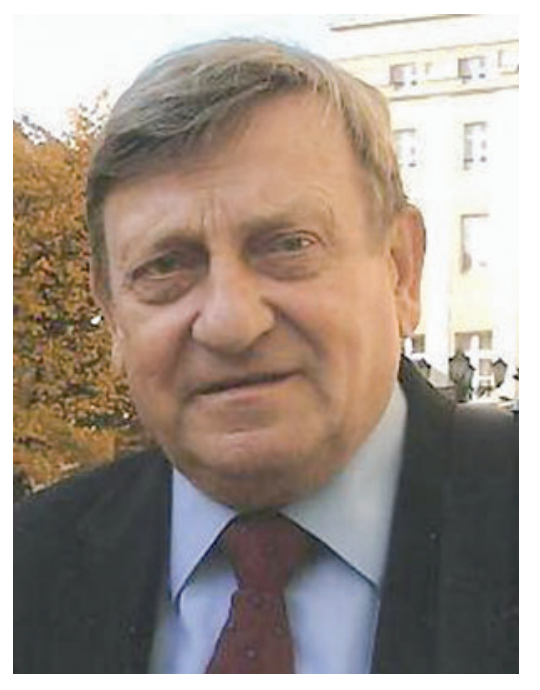

\title{
THROUGH THE MILITARY INSTITUTE OF AVIATION MEDICINE TO A JET PLANE AND A SPACECRAFT
}

\author{
Mirosław HERMASZEWSKI
}

Source of support: Own sources

Author's address: M. Hermaszewski, Warsaw, Poland, e-mail: miroslaw@hermaszewski.com

Abstract: General Mirosław Hermaszewski presents his reminiscences from the period of selection tests conducted at the Military Institute of Aviation Medicine in Warsaw, which aimed at selecting a candidate for the first Polish cosmonaut from among 72 military pilots. The author describes in an emotional way the medical methods and psychological tests, the results of which were the basis for selection. He also mentions episodes from further selection tests conducted in the "Star City" by doctors and space instructors in the USSR.

Keywords: Mirosław Hermaszewski, selection of a Polish candidate for space flight, exciting memories of people and facts encountered on the way of one of the Polish candidates for space flight 
In spring 1961 I was traveling by train from Wołów to Warsaw for my examination at the Military Institute of Aviation Medicine (MIAM) as a candidate to my dreamed-of School of the Eaglets in Dęblin. I could not sleep at night, I was very worried and stressed about the examination. I could still remember two previous failures at the Main Center for Aviation and Medical Examinations in Wrocław. I had undergone examination there twice with a positive result. The only objection was that I was short and underweight. After two years I had gained on weight a little bit and despite the lack of a few kilograms I received a certificate - capable as a candidate for glider training, but with a reservation to fly with an 8-kilogram bag of sand under my seat. It was an awkward situation for me. Nevertheless, I completed the glider training with a high flying time and with a distinction. I did not consider this situation to be my advantage, I was aware of the fact that a jet aircraft requires special health predispositions. At MIAM I met 72 candidates or so. From the first day we were taken under "care" of doctors and other specialists. New emotions and uncertainties appeared in front of each room. I noticed that doctors were not so much looking for healthy candidates, but rather for thosewith some imperfections. There were less and less of us every day. My emotions were rising. On the fourth day there were twelve of us left. Like convicts, we waited for the final results of the committee meeting. The chairman announced that only eight of the candidates passed the examinations. Emotions were at the zenith when they started reading out the names. When I heard mine, I didn't know which group I was in. I was given a certificate. I read it hungrily, and it stated clearly - "Mirosław Hermaszewski capable as a candidate for the Polish Air Force Academy". My joy was impossible to describe. Then, for many years, I underwent similar examinations each year and I never got rid of emotions, even though we were always treated with tender care as "friends". Every year more and more sophisticated procedures were applied, as new planes emerged, so the requirements were also growing. MIAM was responsible for the preparation and fitting of high altitude clothing for the MiG-21 supersonic aircraft, which I soon switched to.

A special experience for me was the extra examination of a group which I was assigned to in the middle of 1976. Candidates with special psychophysical predispositions and high resistance to stress and overload were to be selected. We were accommodated at the premises of MIAM without the possibility of contacting the outside world. The examination looked strange, it

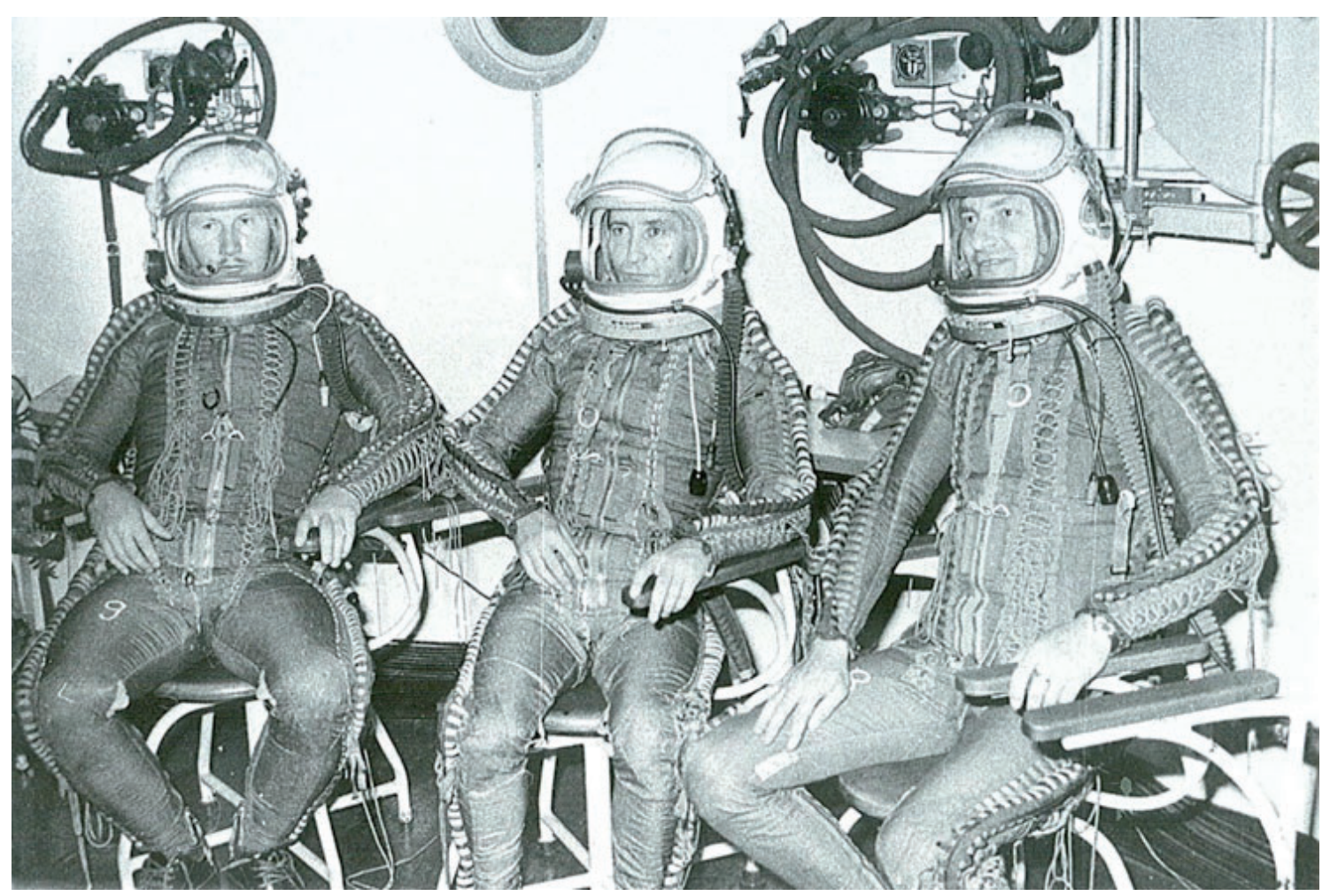

Fig. 1. Examination of candidates for cosmonauts in diving chamber (on the right - mjr Mirosław Hermaszewski, in the middle - It. col. Zenon Jankowski, on the left - mjr Henryk Hałka). 
was different than the annual ones and much more extensive. A doctor captain Krzysztof Klukowski was assigned to take care of the group. The main effort was put on psychological examination which was conducted with precision by Romuald Błoszczyński, PhD, with Jan Terelak, $\mathrm{PhD}$, as his right hand, who established a "file" for each candidate in which he collected information from his own research and observations of other specialists. On this basis, he prepared individual characteristics of the candidates. A real "torture" was the extended laryngological examinations, led by prof. Janusza Kubiczkowa with a whole cast of specialists. Our labyrinths were tortured on "Barany chairs", on Rhõn wheels, gyroscopes and loppings until we lost the will to live. Hot and cold water was alternately poured into our ears and then the reaction of the labyrinth was tested. On overload centrifuges, terminal overloads were generated until we were losing consciousness. I remember that I was able to withstand overloads of up to $8.2 \mathrm{~g}$, which caused astonishment and disbelief in physicians - how is it possible with my height? Tests were repeated. The result was $0.1 \mathrm{~g}$ better. In low pressure chambers we were "taken away" to a height of up to 12 thousand meters and psychological tests were carried out there. As if that wasn't enough, they put us in aviation highaltitude suits and provided us with pure oxygen to breathe, and then gradually replaced it with nitrogen. The experiment was interrupted only when the tested person gave ridiculous answers in the simultaneous psychological tests, or when pencil fell out of his hand and he fell onto his knees. Sessions in low pressure chambers were applied, and then sudden decompression occurred the body was howling with pain and stress.

They looked into the bodies of the tested person in all possible ways. Biochemical analyses were conducted cyclically, and dr. Klukowski would check the pulse and pressure a dozen or so times a day. Before and after exercise tests, before bedtime, after awakening and whenever he wanted to. He had his "file" too and every day he reported to the commander of WIML, col. prof. Stanisław Barański. Many could not survive this race and left the group at their own request. After a month of exhausting examinations, only sixteen of us were left. During fiber-gastroscopic tests, many candidates were found to have bloody petechiae on the stomach walls, which was explained by the effects of many weeks of stress. On the last day of the examination, a doctor threw a suspicion that I had a hiatal hernia. I have never been diagnosed with this ailment and a special proce-

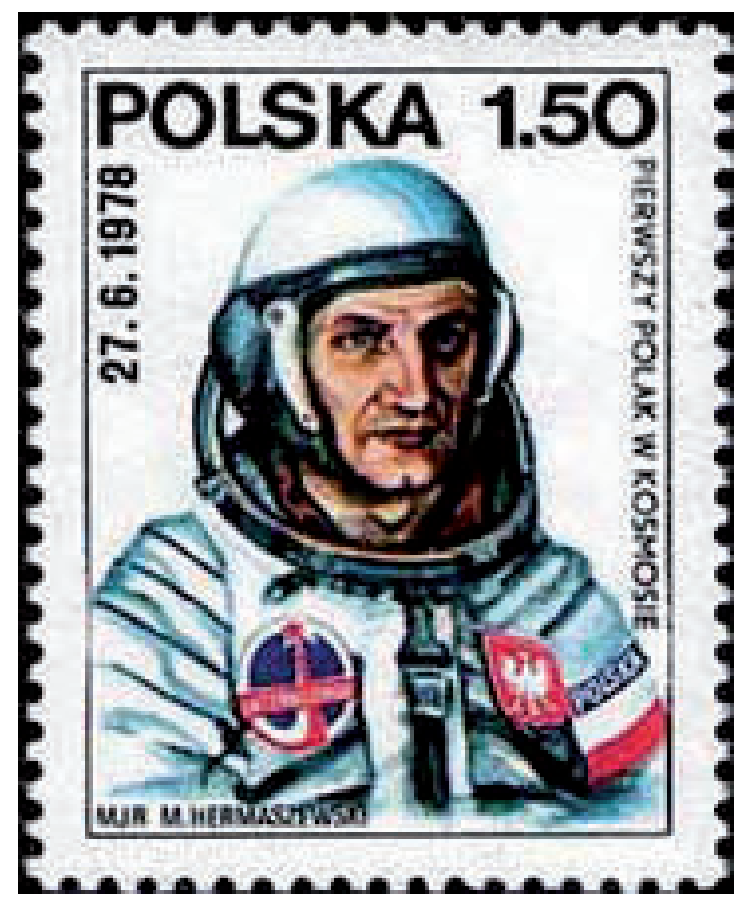

Fig. 2. One of the five millions of occasional stamps prepared by Poczta Polska with the likeness of the first Polish astronaut Mirosław Hermaszewski.

dure was applied to exclude this suspicion. When fasted, in the X-ray room I was given a disgusting white gypsum-like pulp to swallow and a number of photos were taken when I was lying on my back, on the right side and with my head down. No anomalies were found. Soon we were told that this was not about a new type of some hyperplane, but a space flight. Our surprise and amazement had no limits. The next part of our struggle was the "fitness" camp in Mrągowo and Zakopane. There, dr. Klukowski, with his methods (running, exercise tests, skill tests, swimming, cycling time trials, sports games, "mountain tourism" - i.e. running on hiking trails, trainings in low pressure chambers, parachute tower water jumping, catapult training and permanent psychological tests - one day they included 998 questions), caused that after two months of drudgery only five of us were left. We came back to Warsaw to stand before a commission that came from the Cosmonaut Training Center in Star City. Its chairman, a doctor cosmonaut col. Vasily Lazarev analyzed the results of each of us. Together with MIAM specialists, four candidates were selected. There were no objections, but the commission decided that "in order to eliminate doubts" - the pulp and sessions in the X-ray room had to be repeated. The results were positive and so thanks to the head of the Internal Diseases Clinic, dr. Romuald Dąbrowa, 
already in Star City, for the next six months during the monthly examinations I went through the procedure "to eliminate doubts". Unfortunately, my close friend It. col. pilot Andrzej Bugała left the group. The following were qualified to further tests: mjr. pilot Henryk Hałka, It. col. pilot Zenon Jankowski, It. pilot Tadeusz Kuziora and mjr. pilot Mirosław Hermaszewski. The group of four went to Star City for qualification tests. There we met four candidates from the GDR and four from Czechoslovakia. As a result of a three-week tests, two candidates from the GDR and two from Czechoslovakia obtained a certificate of ability. All four Poles were found capable of space flight in terms of health and psychology, which was recognized as a perfect preparation of the candidates by Polish specialists from the MIAM. So Military Institute of Aviation Medicine did a really good job.

The final choice of the ones to fly was made shortly after returning to the country. But this is a different story.

\section{AUTHORS' DECLARATION:}

Study Design: Mirosław Hermaszewski; Data Collection: Mirosław Hermaszewski; Manuscript Preparation: Mirosław Hermaszewski. The Author declares that there is no conflict of interest.

Cite this article as: Hermaszewski M. Through the Military Institute of Aviation Medicine to a Jet Plane and a Spacecraft. Pol J Aviat Med Bioeng Psychol 2017; 23(3-4): 14-17. DOI: 10.13174/pjambp.20.12.2018.03 